\title{
Universalismo: Reflexiones sobre los fundamentos filosóficos de la sociología
}

\author{
Daniel Chernilo ${ }^{1}$
}

\section{Resumen}

Este artículo reflexiona sobre el vínculo entre sociología y universalismo. La tesis central del texto es que, en tanto heredera crítica de las teorías del derecho natural del siglo XVII y la ilustración del XVIII, la sociología adopta la pretensión universalista que de ellas y no puede deshacerse de ese horizonte universalista. Pero si no quiere transformarse en una pieza de museo la disciplina debe repensar constantemente en qué consiste, cuáles son los defectos, y cómo ha de renovar su propia pretensión universalista. La primera sección explora, con la ayuda de Reinhart Koselleck, el vínculo la noción de crisis, el surgimiento de la sociología, y el problema del universalismo. La segunda parte intenta desentrañar la afinidad electiva entre el derecho natural moderno y sociología mediante trabajos de Leo Strauss, Robert Fine y Jürgen Habermas. La tercera sección se centra en la crítica más extendida a la expresión de esa pretensión universalista: su posible eurocentrismo. El texto culmina con algunas consideraciones sobre los desafios que la crítica postmoderna y la nueva ortodoxia globalista le plantean a la forma tradicional en que la sociología ha entendido su horizonte universalista.

\section{Universalism: Reflections on the philosophical foundations of sociology \\ Abstract}

This article reflects on the link between sociology and universalism. Its central thesis is that, as a critical heir of natural law theories of the seventeenth century and of the Enlightenment of the eighteenth century, sociology adopts from them a claim to universalism with which it cannot do away. But if it does not want to become only a antiquarian-piece, the discipline must constantly re-think what is it, what are the shortcomings and how it can renew its own claim to universalism. The first section explores, with the help of Reinhart Koselleck, the linkages between the idea of crisis, the rise of sociology and the problem of universalism. The second seeks to unfold the elective affinity between modern natural law and sociology via works by Leo Strauss, Robert Fine and Jürgen Habermas. The third section centres upon the most extended criticism to the expression of this claim to universalism: its alleged Eurocentrism. The article ends with some comments on the challenges that the postmodern critique and the new orthodoxy on globalization pose to the traditional ways in which sociology has understood its universalistic horizon.

${ }^{1}$ Académico del departamento de sociología de la Universidad Alberto Hurtado e investigador asociado del centro de teoría social de la Universidad de Warwick en Inglaterra. Mis agradecimientos a Omar Aguilar y Luis Campos por su atenta lectura de este trabajo y a Aldo Mascareño por su ayuda, sugerencias y críticas no sólo al texto de este artículo sino al proyecto más amplio del que forma parte. Este trabajo recibe apoyo de FONDECYT (proyectos $1070826 \mathrm{y}$ 1080213). Correo electrónico: dchernil@uahurtado.cl. 
La afirmación de Theodor Adorno de que la sociología es víctima de un tabú antifilosófico no es autoexplicativa - incluso para los estándares de la propia sociología de Adorno que es todo menos autoexplicativa. Por un lado, en el contexto de las ciencias sociales la sociología es la disciplina que mantiene la relación más ambivalente con su propia auto-comprensión de ciencia. La dimensión científica de la sociología - también en su variante positivista - es parte fundamental de su historia e identidad disciplinar. Pero al mismo tiempo ella está bajo el permanente escrutinio - sino ataque - de las versiones más normativas, teóricas e historicistas de la propia sociología. Por el otro, el comentario de Adorno es también curioso porque él mismo representa una tradición altamente reflexiva y filosóficamente orientada en la sociología. Adorno es posiblemente el más filósofo de los sociólogos del siglo XX por lo que tal vez su comentario deba en realidad ser entendido, sino con algo de ironía, como una autocrítica. En este texto no voy a intentar refutar o validar el juicio crítico de Adorno. La advertencia me interesa como invitación a reflexionar sobre una característica específica del trasfondo filosófico de la sociología: una invitación a reconstruirlo y con ello también hacer plausible su rol en el presente y el futuro de la disciplina. Me interesa proponer una vía para conectar la historia de la sociología con su propio pasado filosófico para desde allí empezar a desentrañar algunas de las razones que llevan a la sociología a intentar resolver preocupaciones que no sólo desbordan su auto-comprensión científica, sino que también son constantemente reintroducidas. Me refiero al vínculo entre sociología y universalismo.

La tesis central del texto es que una marcada pretensión universalista caracteriza aquello que podemos denominar conocimiento propiamente sociológico. En tanto heredera crítica de las teorías del derecho natural del siglo XVII y la ilustración del XVIII, la sociología adopta la pretensión universalista de ellas y no puede deshacerse de ese horizonte universalista. Pero ese anclaje histórico le obliga a la propia tradición sociológica, si no quiere transformarse en una pieza de museo con relevancia sólo para quien se interese en la historia de las ideas, a repensar constantemente en qué consiste, cuáles son los defectos, y cómo ha de renovar su propia pretensión universalista.

El artículo se estructura del siguiente modo. La primera sección explora, bajo la guía diestra de Reinhart Koselleck, el vínculo tripartito entre la noción de crisis en uso en los albores de la modernidad, el surgimiento de la sociología y el problema del universalismo. Desde ahí se explican, por un lado, las dimensiones centrales de la pretensión universalista de la sociología y, por el otro, se exploran las consecuencias de esa pretensión para la tensión entre descripción y normatividad al interior de la propia disciplina. La segunda parte intenta desentrañar la afinidad electiva entre el derecho natural moderno y las preocupaciones que dan origen al pensamiento sociológico. Los trabajos de Leo Strauss, Robert Fine y Jürgen Habermas hacen de puente entre ambas tradiciones y permiten sugerir que si bien la sociología surge con la promesa 
de romper con los presupuestos metafisicos del derecho natural, la primera establece una relación ambivalente con el segundo a partir de la pretensión universalista que comparten. La tercera sección se centra en la crítica más extendida a la expresión de esa pretensión universalista en la obra de los sociólogos clásicos: su eurocentrismo. Se intenta mostrar que la respuesta a los defectos eurocéntricos de la sociología no pasan por el abandono de la pretensión universalista, sino por su refinamiento y reflexivización. El texto culmina con algunas consideraciones sobre los desafios que la crítica postmoderna y la nueva ortodoxia globalista le plantean a la forma tradicional en que la sociología ha entendido su propio contenido universalista.

\section{Crisis, sociología, universalismo}

El argumento central de esta primera sección es que el diagnóstico de crisis con que la sociología ha operado tradicionalmente puede explicarse como consecuencia de la orientación universalista en que se funda y que la acompaña hasta el día de hoy. El contexto en el que surgen los conceptos centrales de la disciplina está marcado por la idea de crisis y es desde allí que se arrastran una serie de características distintivas. El rol de la idea de crisis en la autocomprensión del surgimiento de la modernidad ha sido rastreado magistralmente por Reinhart Koselleck, y si bien la reconstrucción que hace este autor de los sentidos premodernos del término no es nuestro foco directo, una breve revisión es ilustrativa para determinar los posibles usos del la idea de crisis en la sociología y de los ámbitos en que resulta aplicable.

En el período de la Grecia clásica, la idea de crisis era "parte de los conceptos centrales de la política" (Koselleck 2007:241) y se refería a la determinación del ordenamiento jurídico justo de la comunidad política. A ello se agrega, también en ese período, su referencia médica a un estado de enfermedad. La crisis en este sentido implica "tanto el estado observable como el juicio (judicium) sobre el curso de la misma que, en un número determinado de días, lleva a la decisión de si el enfermo sobrevive" (Koselleck 2007: 243).Y hay aún otra connotación, de corte más bien teológica, donde el mismo juicio ya referido "contiene también una promesa de salvación" (Koselleck 2007: 242). La posterior transformación latina del término la inserta aún más en el contexto de los asuntos sociopolíticos para pasar a indicar "aquel período del tiempo en el que la decisión es inminente, pero aún no ha recaído" (Koselleck 2007: 243).

En los albores de la modernidad, la idea de crisis comienza a adquirir una creciente centralidad. Koselleck distinguirá para ese período tres campos principales en los que se apela al concepto de crisis y con ellos nos acercamos al momento en que su inclusión en el léxico sociológico se hace detectable: una función "histórico-discriminante y sentenciadora", una "médico-diagnóstica" y una "teológico-evocativa" (Koselleck 2007: 253). Desde el punto de vista histórico, ya desde finales del siglo 
XVIII “"crisis' se convierte en signatura estructural de la Época Moderna” (Koselleck 2007: 251). La noción misma de crisis "se convierte en el concepto supremo, temporalmente elástico de los modernos" (Koselleck 2007: 255). El resultado es que la crisis es simplemente otra forma de referirse al tiempo presente, con lo que "crisis" pasa a ser, sencillamente, un concepto estable para 'historia' (Koselleck 2007: 250) y la modernidad deviene en aquel período histórico marcado estructuralmente por una crisis crónica. La función médico-diagnóstica de la idea de crisis se refiere a la acción de agentes internos o externos al cuerpo político o social que desencadenan un estado de cosas nuevo. Pero la adopción del juicio crítico respecto a qué consiste la crisis no es lo central: más importante es cómo ha de tratarse al paciente ya sea para restaurar el status quo ante o para establecer un nuevo orden.Y en su orientación teológica, lo que prima es la recurrente apelación a un orden superior u objetivo con el que se intenta entregar sentido no sólo a eventos específicos al decurso histórico como un todo. "Sobre la base de la promesa del 'último día' que habrá de venir, 'crisis' puede definirse como la última decisión histórica, tras la que la cualidad de la historia experimenta un cambio fundamental" (Koselleck 2007: 251). La forma específica en que la historia de la sociología se enlaza con la del concepto de crisis dice relación con su condición de ser la ciencia dedicada a ella de manera prioritaria. Comte da un paso al frente y hace suya la tarea: "se precisa una especie de ciencia de la crisis, que conozca la sociedad y las leyes de su historia” (Koselleck 2007: 255).

Habiendo abusado del trabajo de Koselleck, quiero proponer ahora que cuando la sociología habla de crisis está haciendo por lo general mención a dos tipos distintos de crisis. Por un lado, la gran mayoría de los diagnósticos epocales de la sociología refieren a un estado de crisis social - más o menos agudo y con un contenido o causa específica también cambiante. La crisis se expresa no sólo en el rompimiento traumático con un estado de cosas anterior, sino también en la comparación entre ese estado de cosas que se constata empíricamente y las posibilidades últimas a él asociado que se asume como situación ideal con valor universal. No se trata sólo de que países periféricos y zonas subdesarrolladas sean la versión imperfecta de aquello que tiene lugar en Europa - aunque el Eurocentrismo es sin duda parte del problema y más adelante algo tendremos que decir sobre él. Respecto de la pretensión universalista de la sociología, es aun más importante comprender que la crisis dice relación con que incluso aquello que tiene empíricamente lugar en Europa es expresión insuficiente de sus propias posibilidades evolutivas:"El trasfondo de esta crisis permanente es la discrepancia entre una estructura social cambiante y los siempre inadecuados regímenes políticos, que por eso mismo han perdido su legitimidad" (Koselleck 2007: 260). El diagnóstico de crisis dice relación con las consecuencias negativas que esta situación de potencialidades internas no realizadas tiene a todo nivel.

Pero la sociología opera con otro diagnóstico de crisis respecto de los fundamentos de su propio quehacer como disciplina científica - y a este respecto la utilidad de la 
reconstrucción de Koselleck es algo más indirecta. Se trata en este caso de una crisis más bien congnitiva que se expresa en un escepticismo sobre la validez de sus propios conceptos centrales y estrategias metodológicas. La sociología sufre con el hecho de tener que hacer afirmaciones sobre la base de presupuestos crónicamente problemáticos y vuelve a sufrir con el hecho de que esas explicaciones son recibidas con frialdad por los actores en sus mundos de la vida. Sin duda, esta interrogación sobre la adecuación de los procedimientos para generación de conocimiento sociológico puede tornarse algo cínica - con la igualación entre sociología e ideología - y tener asimismo consecuencias paralizantes - con la igualación entre sociología y epistemología. La crisis cognitiva de la sociología puede entonces entenderse como la aporía generada a partir de la afirmación del carácter histórico y socialmente condicionado de su saber y, simultáneamente, del intento por trascender ese mismo postulado para hacer posible el desarrollo de explicaciones que sean efectivamente superiores a las del sentido común de los actores legos - y que los propios actores habrán de reconocer como tales (Habermas 1990, Kim 2005).

El elemento que está a la base de esta peculiar forma que la sociología tiene de entender el mundo social y sus propios procedimientos se encuentra, en mi opinión, en la orientación universalista que está en el fundamento de la disciplina.Tanto en el caso de la observación de la sociedad como en el de la autorreflexión sobre la validez del conocimiento sociológico, el postulado de la crisis presupone una distancia entre el registro empírico de lo que se observa y aquel estado de cosas ideal que se habría esperado encontrar o conseguir: la sociedad no se mueve en la dirección supuesta, las metas alcanzadas no producen las consecuencias esperadas, los actores se resisten a reconocer la primacía del conocimiento sociológico que a su vez duda sobre sí mismo una y otra vez. En otras palabras, la problemática auto-comprensión científica de la sociología la lleva a concentrarse en el registro de lo que es, pero sus preguntas, conceptos y métodos la empujan al mismo tiempo a ir más allá para incluir toda clase de explicaciones, comparaciones y evaluaciones con el fin de intentar comprender y resolver la distancia entre lo que es y lo que podría o debiera ser. Nuevamente puede salir Koselleck a nuestro rescate: “'Crisis' se convierte en un punto de intersección de la situación actual y sus condiciones histórico universales, sin cuyo conocimiento no es posible efectuar un pronóstico" (Koselleck 2007: 255). Se reafirma así no sólo el vínculo inmanente entre sociología, modernidad y la propia noción de crisis, sino que este concepto moderno de crisis no puede entenderse como independiente de la pretensión universalista de la propia modernidad:"el concepto de crisis adquiere la función de describir, y aun de evocar, una transición histórico-universalmente única, pero también progresivamente consolidada" (Koselleck 2007: 257).

El registro exhaustivo de eventos empíricos, la explicación de las causas últimas de esos eventos como tendencias generales de la sociedad moderna, la validación de los métodos con que se llevó a cabo tal registro y explicación, así como la evaluación 
normativa de esos eventos y tendencias respecto de un estándar superior, se han mostrado todas como tareas propias de la disciplina. Planteadas las cosas de esta manera, el argumento que quiero sostener es que el conocimiento sociológico se constituye en el intento por hacer más abstractas, reflexivas o refinadas:

(1) las definiciones sobre el elemento conceptual que ha de permitir capturar la naturaleza última o momento fundante de lo social;

(2) los métodos para controlar las distorsiones que se producen en el intento por registrar de manera fidedigna lo social y;

(3) la comprensión de la crisis social que surge del despliegue insuficiente o incorrecto de las propias posibilidades evolutivas de la sociedad moderna;

En el nivel conceptual, el trabajo, el sentido mentado de la acción, la moral, la intersubjetividad, la sociedad, la interacción lingüística o las selecciones comunicativas son todas formas de referirse a aquel componente definitivo que constituye las relaciones sociales de manera universalista. Cada uno de estos conceptos guía la investigación sociológica en distintas direcciones, pero todos tienen en común el intento por definir aquel elemento fundante de lo social que habría de permitir a la sociología investigar, en los contextos históricos y socio-culturales más diversos, aquello que surge cuando dos o más seres humanos se relacionan mutuamente. De manera similar, a nivel metodológico la sociología intenta construir aquel conjunto de estrategias, protocolos y reglas con las que validar sus propias observaciones y explicaciones de lo social. Desde la dialéctica hasta la encuesta, pasando por los tipos ideales y los relatos etnográficos, los métodos de investigación sociológica operan bajo el supuesto universalista de la comprensibilidad de las acciones humanas por individuos que no forman, ni llegarán nunca a ser parte, del grupo en estudio.Y aún cuando se asume que inevitablemente se producirán importantes distorsiones, se opera igualmente bajo la expectativa de que a pesar de esas dificultades, los sentidos, motivaciones, actitudes, valoraciones, expectativas y prejuicios de los actores pueden ser registrados y estudiados con posterioridad.Y en lo que respecta a la crisis social que la sociología diagnostica, la pretensión universalista dice relación con el develamiento de los obstáculos que impiden la expresión cabal del momento fundante de lo social: alienación en el caso del trabajo, jaula de hierro en el caso del sentido de la acción o comunicación sistemáticamente distorsionada en el caso de la interacción lingǘstica. Una consecuencia que a mi juicio se deriva de este entendimiento de la pretensión universalista de la sociología es que permite acercarse al problema de la dificil relación entre descripción y normatividad en la disciplina. Como ya se dijo, la propia auto-comprensión científica de la sociología incluye una dimensión normativa que tradicionalmente le ha estado cerrada, no sólo a las ciencias naturales sino que se ha ido cerrando progresivamente durante el siglo XX también en disciplinas afines como la ciencia política o la economía (Habermas 1989). La pretensión uni- 
versalista con que opera, tanto a nivel conceptual como metodológico, da impulso a una reflexión que no puede mantenerse ni resolverse dentro de parámetros que son propios de las disciplinas científicas, pero que al mismo tiempo está integrada al quehacer y modo de reflexión de la sociología. La ilusión de abandonar toda pretensión normativa se ha probado insuficiente para los propios practicantes de la disciplina. Ello podría explicar el por qué la sociología, a pesar de su permanente interés por cuestiones normativas, cuando se deja instrumentalizar políticamente lo hace exclusivamente de manera imperfecta. No es sólo, como bien lo ha señalado Habermas (1987: 278), porque la sociología conservadora y la sociología crítica son co-originarias desde su fundación en el período de la revolución francesa, es decir, porque "ha surgido en la misma medida tanto el espíritu de la Revolución como el de la Restauración; cada uno de los bandos de la guerra civil la reclamó para sí”. Sino también, porque si bien la sociología se interesa en la dimensión normativa de la vida social y presta constantemente sus servicios a distintas causas políticas, en el proceso de abrazar posiciones normativas termina por defraudar tanto a quienes fueron en su busca como a sí misma. Parte de su vocación fundamental está simplemente en otro lado y, para seguir siendo sociología, no puede sino abandonar la causa política a mitad de camino, cuando empieza a hacer exigencias poco convenientes para la coyuntura o exponer verdades incómodas.

Pero en la medida que el ingreso permanente de la sociología en cuestiones normativas se entiende como consecuencia de su universalismo cognitivo, ese mismo universalismo impone restricciones al tipo de orientaciones normativas que pueden efectivamente justificarse desde una perspectiva sociológica. El interés sociológico por cuestiones normativas resulta de una suerte de rebalse de su universalismo cognitivo: es la pretensión de conocimiento sociológico la que la empuja hacia cuestiones que no pueden resolverse sólo como cuestiones descriptivas o explicativas sino valorativas. El ingreso de la sociología al debate normativo se hace, por decirlo de algún modo, desde dentro del marco de referencia que su universalismo cognitivo crea.Y si bien desde allí no se deriva la existencia de una única normatividad sociológica, tampoco resulta posible justificar cualquier proposición normativa con medios sociológicos. El universalismo cognitivo de la sociología ha tendido - o debiera tender - a bloquear el desarrollo de explicaciones y posiciones normativas particularistas de todo tipo: culturalistas (identidades esenciales que impiden o garantizan actitudes de tal o cual tipo), nacionalistas (cuerpos colectivos con rasgos de personalidad distintivos), raciales (sólo algunos grupos califican como seres humanos para todo efecto), de género (diferencias entre hombres y mujeres que en sí mismas explican diferencias de comportamiento) o incluso de clase (finalmente, no hay ni una ciencia proletaria ni una burguesa). Los conceptos y métodos de la sociología requieren de, y a la vez presuponen, una concepción universalista de la especie humana que abarca a todos los individuos y grupos humanos. La pretensión universalista de la sociología debe poder registrar, conceptualizar y explicar toda clase de relaciones sociales - realmente todas 
- de manera universalista. Sólo aquellas posiciones que abrazan el universalismo normativo que asume la idea de una única especie humana cumplen con esta condición y ellas son por tanto las que resultan compatibles con el universalismo cognitivo en que se funda la sociología.

El argumento que aquí se propone no dice relación con la determinación de cuántos colegas, y en qué períodos, han privilegiado esas u otras posiciones - hace algún tiempo ya hicimos una evaluación preliminar de cuán extendidas están ese tipo de explicaciones particularistas en la sociología de América Latina (Chernilo y Mascareño 2005). Me interesa sostener que la pretensión universalista cognitiva puede ser reconstruida a partir del corpus central de la disciplina y que su correlato normativo, aunque menos aparente, puede ser igualmente reconstruido. La orientación cognitiva fundamental de la sociología tiende a privilegiar aquellos conceptos, métodos y proposiciones normativas que sean capaces de referirse al desarrollo de la modernidad como logro evolutivo de la especie humana en su conjunto.Y a partir del dato básico de la modernidad como constatación de la impredecible variabilidad sociocultural y normativa de las relaciones sociales, lo hacen desde un universalismo que no puede ser homogeneizante sino que es pluralista desde el inicio. Parafraseando a C.W. Mills (1994), esta pretensión universalista puede entenderse como la gran promesa de futuro de la sociología. Pero es también su orientación fundacional.Y para ello debemos explorar el origen de la pretensión universalista de la sociología en la tradición moderna del derecho natural.

\section{Derecho natural, universalismo, sociología}

El tema de los orígenes intelectuales de la sociología ha convocado la atención de una serie de sociólogos y filósofos notables, siendo varias las respuestas que se han entregado al respecto. A la sociología se la presenta por lo general como la heredera algo díscola de la filosofia de la ilustración (Aron 1965, Cassirer 1979, Gay 1973, Heilbron 1995, Parsons 1968, Seidman 1983), como parte de la reacción romántica contra la propia ilustración (Hawthorn 1987, Nisbet 1967) y por cierto como reflexión crítica sobre el carácter intrínsecamente contradictorio del capitalismo como expresión fundamental de la vida social moderna (Giddens 1971, Marcuse 1979, Zeitlin 1990). Sin intentar contradecir directamente estas interpretaciones, la hipótesis que propongo es que hay una suerte de afinidad electiva entre derecho natural y sociología que viene dada justamente por la pretensión universalista que ambas comparten. No se trata, por cierto, de afirmar que la sociología no es otra cosa que un apéndice del derecho natural moderno - como sí se lo ha hecho en relación con la filosofía política (d'Entrèves 1973). Tampoco es mi intención establecer un vínculo causal que, saltándose el período de la ilustración en el siglo XVIII, conecte directamente el surgimiento de la sociología con las teorías del derecho natural del siglo XVII. Se trata 
de intentar establecer una conexión donde tanto sus afinidades como sus diferencias puedan desplegarse.

Siguiendo el estudio de Michael Löwy sobre la afinidad electiva entre el pensamiento mesiánico judío y las utopías radicales de principio del siglo XX en Europa central, la idea de afinidad electiva puede entenderse como "una relación interna rica y llena de sentido entre dos configuraciones" que se asumen como distintas (Löwy 1992: 9). La tesis de Löwy es instructiva en este contexto porque a su juicio tanto el mesianismo judío como el radicalismo de inicios del siglo XX comparten una cierta noción de redención que si bien se expresa de manera distinta en cada tradición - religiosa en el primer caso y política en el segundo - comparten una visión restauradora del pasado, la idea de un evento crítico que transforma de manera radical el presente y un sentido de utopía futura. De manera análoga, la elección de la afinidad electiva como estrategia metodológica para estudiar el vínculo entre sociología y derecho natural se justifica a través de la tesis de que ambas tienen una pretensión universalista. Esa pretensión universalista le permite tanto a la sociología como al derecho natural hacer frente al problema de la distancia entre estándares suprahistóricos y diferencias socio-culturales - tanto desde una perspectiva primordialmente normativa, para el caso del derecho natural, o desde una perspectiva de corte más cognitiva para el caso de la sociología. La afinidad electiva se expresa tanto en las similitudes o continuidades entre los dos momentos que se espera estudiar - es una "cierta clase de conexión entre fenómenos aparentemente distintos dentro del mismo campo cultural (religión, filosofia, literatura)" (Löwy 1992:10) - pero intenta al mismo tiempo capturar sus diferencias y especificidades en una "elección mutua que implica una distancia previa, un vacío intelectual que debe llenarse, una cierta heterogeneidad ideológica" (Löwy 1992: 12).

Vistas las cosas de este modo, lo primero que se constata es que ambas tradiciones son distintas. La literatura recién referida sobre el surgimiento de la sociología poco y nada se interesa en el derecho natural; y entre quienes han reconstruido la tradición del derecho natural, la sociología simplemente parece no existir (Haaknossen 1996, Hochstrasser 2000, Tuck 1981). En todo caso, sí es posible encontrar trazos de este vínculo en relación a temas concretos. Las teorías de los sentimientos morales de Adam Smith se ha puesto en relación con la preocupación posterior de la sociología sobre la integración social (Swingewood, 1970); la teoría de la sociedad civil de Adam Ferguson en relación a la división social del trabajo (Barbalet, 2005) y la teoría de la paz perpetua de Kant en relación a las teorías cosmopolitas de Jürgen Habermas (Fine 2007, Chernilo 2007c).Y es también posible mencionar tres trabajos en que tal conexión se ha intentado hacer más explícita y de cada uno de ellos hay lecciones que sacar. 
Cronológicamente, el primero que parece haber intentado establecer una relación entre ambas tradiciones es Leo Strauss. Su argumento apunta en todo caso en una dirección distinta a la que aquí se propone puesto que más que el establecimiento de una continuidad o afinidad electiva entre derecho natural y sociología, su interés se centra en demostrar que la futilidad actual de la segunda se debe justamente a su abandono de la primera. Dice Strauss (1974 [1950]: 2): "de acuerdo a nuestra ciencia social, podemos estar instruidos o llegar a instruirnos en asuntos de importancia secundaria, pero nos tenemos que resignar a la ignorancia absoluta en el aspecto más importante: no podemos tener conocimiento alguno sobre los principios últimos de nuestras opciones". La ciencia social que Strauss (1974:36) así critica se expresa de forma paradigmática en el trabajo de quien, "cualesquiera puedan haber sido sus errores, es el más grande científico social de nuestro siglo": Max Weber. El punto de partida de la crítica de Strauss es su agudo reconocimiento de que la ciencia social libre de valores de Weber no puede entenderse simplemente como un tipo de relativismo historicista: "Él se separa de la escuela histórica no porque haya rechazado las normas naturales, por ejemplo, normas que son universales y objetivas, sino porque ésta intentó establecer estándares que eran sin duda históricos y particulares pero aún objetivos. [Weber] se opuso a la escuela histórica no porque ella eliminase la idea de derecho natural sino porque, en vez de rechazarlo completamente, mantuvo el derecho natural de manera histórica" (Strauss 1974: 37). Lejos de rechazar la posibilidad de establecer proposiciones con validez universal, el problema para Weber es que tales proposiciones sólo podrían referirse a aquellas cuestiones sobre las que la ciencia puede dar respuesta de manera empírica. En eso consiste lo que Strauss denomina el "nihilismo noble" de la sociología de Weber: "la verdadera razón de por qué Weber insistió en el carácter éticamente neutral de la ciencia social (...) no era su creencia en la oposición fundamental entre lo que es y lo que debe ser, sino su creencia de que no puede haber ningún conocimiento genuino de lo que debe ser" (Strauss 1974: 41). Esta cerrazón frente al carácter eminentemente normativo de la vida social la explica Strauss por el hecho de que la sociología le ha dado la espalda a la tradición intelectual que está a su base y que pudo eventualmente haberle proveído del instrumental para plantearse tales preguntas: el derecho natural.

Otro intento indirecto por desplegar esta conexión lo encontramos en Robert Fine (2002), quien hizo de este tema el hilo conductor de su reconstrucción de la problemática relación de Marx con la tradición de lo que él para esos efectos llama la jurisprudencia clásica: Hobbes, Montesquieu, Rousseau, Adam Smith, Kant y Hegel. La tesis de Fine en ese trabajo es que la ruptura de la jurisprudencia clásica - el derecho natural moderno - es tan radical como insuficiente: "El problema con la jurisprudencia clásica no fue su rompimiento con la teoría tradicional de la ley natural sino más bien el que no consiguió completar el rompimiento. Abolió la teoría de la ley natural en su forma tradicional sólo para hacerla resucitar en una forma moderna" (Fine 202: 21). Fiel a su estilo, el argumento de Fine es que entre mientras dos 
formas de pensamiento más intentan explícitamente separarse, crece la posibilidad de una inesperada e incómoda confluencia. De esa manera, "tomados como unidad, los teóricos de la jurisprudencia clásica demolieron las concepciones tradicionales de la ley natural, pero al hacerlo naturalizaron la ley positiva" (Fine 2002: 66). Fine demuestra de esta forma que, lejos de rechazar esa tradición de pensamiento jurídico como simplemente ideología burguesa, Marx habría batallado por encontrar el elemento racional (universal) que allí se encuentra para integrarlo a su propia teoría. En ese proceso, el momento en que Marx rompe con la tradición del derecho natural - su forma ingenua o ideológica de entender las relaciones de clase, el idealismo ahistórico de sus explicaciones supuestamente históricas - debe entenderse como complemento y no como negación absoluta de los temas fundacionales de la misma - la búsqueda de una organización justa de las relaciones sociales sobre la que fundar un orden social racional (Fine 2001: 85-98).

El tercer antecedente para indagar en las conexiones entre derecho natural y sociología lo encontramos en los estudios sobre las relaciones entre teoría y praxis del entonces treintañero Jürgen Habermas. El énfasis está ahora en la forma que los primeros conceptos de historia, orden, progreso y derecho con que surge la sociología se encuentran fuertemente anclados en la tradición del derecho natural:"el concepto de una historia natural de la humanidad en progreso hacia lo cada vez mejor (...) apadrinó a la sociología” en su período de formación (Habermas 1987: 287).

Desde un punto de vista filosófico, el acto fundacional de la modernidad política es un acto de restauración donde preceptos del derecho natural tradicional se invocan para reestablecer un (imaginario antes que real) status quo ante: "'evolución del derecho natural' fue el concepto filosófico que la revolución se formó de sí misma tan pronto como fue conceptuada como revolución - en la separación de las colonias americanas de la madre patria y, sobre todo, en la caída de Ancien Régime" (Habermas 1987: 87). En los hechos, sin embargo, el acto fundante que se expresa en la declaración de derechos fundamentales no sólo debe hacer frente a un nuevo tipo de relaciones sociales - la liberación del tráfico de mercancías entre las que se comienza a incluir el propio trabajo humano - sino que problematiza la forma en que este nuevo tipo de orden social ha de buscar legitimidad:"Este acto de declaración debía exigir para sí engendrar el poder político exclusivamente a partir de la comprensión filosófica. Esta idea de la realización política de la filosofia, a saber: la creación autónomo-contractual de la coerción jurídica a partir tan sólo de la coerción de la razón filosófica, es el concepto de revolución que se sigue inmanentemente de los principios fundamentales del derecho natural moderno" (Habermas 1987: 90).

Haber mas muestra con ello que la pregunta sobre el fundamento normativo del orden social moderno se separa, pero también descansa y presupone, el fundamento de racionalidad que le provee el marco normativo del derecho natural. Ello podría 
explicar por qué todas las reconstrucciones y los análisis más sofisticados sobre la tradición de la ley y el derecho natural enfatizan que aún cuando parece habérselo matado una y mil veces, el derecho natural reaparece en la modernidad de distintas formas y, por cierto, con distintos colores políticos (d'Entrèves 1973, la Torre 2006).

Para terminar de hacer plausible mi argumento sobre la afinidad electiva entre sociología y derecho natural a partir de la pretensión universalista que ambas comparten, es aún necesario decir algo más sobre la propia pretensión universalista. Como ya se anunció, en las teorías del derecho natural la pretensión universalista se expresa primordialmente en el nivel normativo mientras que en la sociología prima el nivel descriptivo. Que el derecho natural privilegie lo normativo y la sociología lo descriptivo, de más está decirlo, no significa que cada una se interese exclusivamente en ese plano sino simplemente que es allí donde ha hecho su contribución principal. Véase, por ejemplo, la forma en que Heinrich Rommen - un abogado católico alemán que terminó en el exilio durante el régimen Nazi - expresaba en 1936 el problema del surgimiento de la tradición temprana del derecho natural:

La idea de una ley natural sólo puede surgir cuando los hombres empiezan a percibir que no toda ley es una ley divina inalterable e inmutable. Puede surgir sólo cuando la razón crítica se da cuenta, al mirar históricamente para atrás, de los cambios profundos que han acaecido en la ley y costumbres reales y se hacen concientes de la diversidad de instituciones morales y legales de su propio pueblo en el transcurso de la historia.Y cuando, además, al mirar más allá de los confines de su propia ciudad estado o tribu, se da cuenta de la diferencia con las instituciones de los pueblos vecinos. Cuando, por lo tanto, la razón human sorprendida al constatar esta diversidad, llega por primera vez la distinción entre la ley divina y la ley humana (Rommen 1998: 4)

Si se eliminan las referencias a la ley divina y se las reemplaza por referencias más racionalistas, el argumento aparece de un modo bastante similar en el propio Leo Strauss (1974:23-4). A su juicio, la historia parece probar la tesis que

todo el pensamiento humano, y sin duda todo el pensamiento filosófico, se refiere a los mismos temas o problemas fundamentales; existe, por lo tanto, un marco de referencia inmutable que permanece frente a todos los cambios del conocimiento humano tanto de hechos como de principios. Esta inferencia es obviamente compatible con el hecho de que la claridad sobre estos problemas, el cómo se los enfoca y las soluciones que se sugieren cambian de pensador a pensador y de época en época. $\mathrm{Si}$ los problemas fundamentales permanecen frente a todo cambio histórico, el pensamiento humano es capaz de trascender sus limitaciones históricas o de capturar algo que es transhistórico. Este sería verdad incluso si fuese cierto que todos los intentos por resolver estos problemas están destinados a fallar y que están destinados a fallar en razón de la 'historicidad de 'todo' el pensamiento humano 
Hay dos cosas que me importa destacar antes de cerrar esta sección. Primero, la sociología surge, en ruptura con el corpus de la filosofia política anterior, con el objeto de dar cuenta de la variabilidad histórica y socio-cultural que caracteriza la vida moderna. Se hace necesario comprender, comparar y en definitiva evaluar esas diferencias y la observación sociológica se transforma en el instrumento más adecuado para esa tarea. Pero esta nueva forma de filosofia política empírica (Wagner 2001), intenta tan decididamente romper con su herencia que termina por rejuvenecerla. Dicho en la terminología que prefiere Koselleck (2007: 253), la modernidad como crisis es "histórico-conceptualmente" posible sólo porque "el concepto político de crisis, mediante un enriquecimiento teológicamente alimentado, en el sentido del juicio final, fue elevado a la categoría de concepto filosófico-histórico epocal". La naciente sociología es todavía una forma de filosofía política que no renuncia a la pretensión universalista que está en el centro de su propia tradición. Pero ya no es sólo filosofía política sino que también la naciente ciencia empírica de lo social. Segundo, con la idea de afinidad electiva se pretende hacer presente tanto la inserción de la sociología en una tradición intelectual de más larga duración como el tipo de aporte específico que ella hace. Para comprender su vínculo desde el punto de vista de la pretensión universalista es necesario hacerse igualmente cargo de ambos momentos. Ambas intentan proponer estándares suprahistóricos con alcance universal vis-à-vis la evidente variabilidad histórica y sociocultural de la experiencia humana Pero para que sea propiamente afinidad electiva debe notarse también la distancia real que hay entre los elementos que se relacionan: en el derecho natural el universalismo es predominantemente normativo o religioso y en la sociología predominantemente cognitivo o científico. De ello se sigue que los modos de operar y preocupaciones centrales de ambas son distintos y tienen consecuencias distintas.

La pretensión científica de la sociología indica que son sus conceptos y procedimientos metodológicos los que guían su orientación normativa. El universalismo normativo de la sociología clásica - su orientación cosmopolita basada en el supuesto de la unidad de la especie humana - es resultado del universalismo cognitivo con que se fundan sus conceptos y métodos más importantes (Chernilo 2007b). En las teorías del derecho natural, por el contrario, es la pretensión normativa de la unidad del mundo - natural, social y trascendente - así como la existencia de leyes generales que valen para todos los seres humanos, lo que obliga a buscar evidencias empíricas que permitan reforzar la creencia en esa unidad original. En otras palabras, mientras que para la sociología el universalismo normativo es una exigencia del universalismo con que se orientan sus conceptos centrales y métodos de investigación, para las teorías del derecho natural el universalismo normativo es el punto de partida y el esfuerzo cognitivo que puede llegar a desplegar se encuentra subordinado a esa fe. A la sociología le pasa que, sin proponérselo, no puede sino terminar afirmando la unidad de la especie humana porque así se lo indica el desarrollo de unas reglas del método o tipos ideales que pretenden organizar los resultados de investigaciones en 
distintos contextos culturales y períodos históricos. Si los métodos y conceptos han de mostrar su utilidad universal, entonces todos quienes pueden ser estudiados con esos métodos han de poseer al menos alguna característica común que los haga parte de la misma especie.

\section{Universalismo, eurocentrismo, sociología clásica}

Hasta aquí he intentado hacer plausible la conexión entre universalismo y sociología tanto en lo que se refiere al contexto de crisis en que la disciplina surge - y se propone estudiar - como en su relación con la tradición intelectual del derecho natural. Una posibilidad sería ahora entregar apoyo textual para mi tesis en la obra de los primera generación de sociólogos - desde Marx a Simmel - pero esa reconstrucción ya está hecha y no tengo por ahora nada nuevo que agregar al respecto (Chernilo 2007b, 2008b).Voy, en todo caso, a repasar los lineamientos generales de esa discusión pero con el objetivo de reflexionar sobre el desafio que la crítica de eurocentrismo, tal vez si la más representativa de las críticas que se le han hecho a la sociología clásica, le plantea a la tesis de la pretensión universalista que he venido sosteniendo.

Tal vez como consecuencia de la poca atención que le prestó a su relación con las teorías del derecho natural, los trabajos mencionados al inicio de la sección anterior tampoco hicieron mayor asunto de la pretensión universalista que orienta la actividad intelectual de los sociólogos clásicos. Sin llegar a sostener que esa literatura pasó completamente por alto el rol de la pretensión universalista de la sociología clásica, sí es cierto que no fue lo suficientemente explícita en su tratamiento. La pretensión universalista con que operaba era algo equívoca puesto que cuando se la reconoce queda subordinada, cognitiva y normativamente, al supuesto interés de los primeros sociólogos por comprender las características más importantes de los nacientes estados-nación europeos. Entre la década de los sesenta y los ochenta del siglo XX, la orientación universalista de la idea de crisis que revisamos en la primera sección desaparece crecientemente y con ello la narración sobre el decurso histórico de la sociología devino en la idea de una naciente ciencia dedicada al estudio de la organización estatal de la vida colectiva europea durante el período de instalación del capitalismo en ese continente. La reconstrucción de la sociología como ciencia dedicada al estudio de la doble revolución industrial y política con que surge la modernidad, en vez de concentrarse en la aspiración potencialmente universalista de esos procesos (Hobsbawm 2001), habría privilegiado su dimensión nacional - inglesa y francesa. El fenómeno a estudiar ya no es la gran tensión entre surgimiento local y aspiración y expansión global del capitalismo y la democracia política, sino el carácter endógeno y culturalmente específico de ambas revoluciones. La sociología tiene entonces mucho para decir sobre lo que sucede al interior de las nacientes sociedades nacionales europeas, pero todo aquello que habría afirmado, o habría podido afirmar, sobre otros ámbitos o espacios geográficos más allá de Europa debe entenderse 
siempre de manera subordinada a su esfuerzo prioritario por comprender y explicar las fenómenos más importantes acaecidos en las metrópolis nacionales (Dahrendorf 1958, Giddens 1973, Martins 1974, Smith 1979, 1983). Aparece entonces una pretensión universalista, pero reificada: la elevación apresurada y poco fundamentada de una serie de patrones geográfica e históricamente particulares a ley evolutiva de la humanidad. El eurocentrismo que así aparece es tremendamente problemático, pero en la medida en que no hay una preocupación explícita por la pretensión universalista de la sociología dificilmente podemos distinguir el eurocentrismo que efectivamente aparece en los trabajos de la primera generación de sociólogos y cuánto de lo que se dice sobre sus trabajos es en realidad la imputación problemática de reconstrucciones posteriores.

La naciente teoría social habría operado entonces con una doble reducción estatista y nacionalista. El lado estatista de la reducción se expresaría en la seducción que el poder del Estado habría ejercido en los sociólogos clásicos. Representada de forma paradigmática en la definición del Estado como agencia que guarda para sí el monopolio del uso de la violencia legítima, la conceptualización weberiana puede sin problemas interpretarse como una exaltación acrítica de la extraordinaria capacidad de control y conducción del Estado moderno (Weber 1993).Y tampoco Durkheim habría estado exento de este reduccionismo estatal cuando, en sus clases para estudiantes de pedagogía, se refería al carácter eminentemente moral del Estado y a su rol como centro organizativo de la vida colectiva moderna (Durkheim 1966) - o cuando entregaba a la Francia de la Primera Guerra Mundial el rol de garante de la civilización occidental en contra de una Alemania enloquecida por sus ansias de poder (Durkheim 1915). Si la reducción estatal se expresa en una interpretación politizada de textos con intención analítica, la supuesta reducción nacionalista aparece de forma aún más espectacular, y se expresaría en la casi nula atención que la sociología clásica habría manifestado en el tema. Lo nacional sería una especie de punto ciego en la obra de los primeros sociólogos, punto ciego que hace de lo nacional el supuesto fundante de la disciplina: la sociología no tiene nada para decir sobre la nación porque para ella la nación lo es todo y está en todas partes (Albrow 1996, Beck 2000, 2006, Urry 2000). No sólo Weber y Durkheim sino incluso Simmel habría sido un nacionalista a pesar de sí mismo (Harrignton 2005).Y las oscilaciones de Marx respecto a la cuestión nacional - su defensa del colonialismo británico en la India, su tratamiento despectivo de las nacionalidades eslavas como "pueblos sin historia", la ironía con que se refiere a los procesos de independencia latinoamericana, así como su ambivalente internacionalismo al interior de Europa, serían todas expresión de la misma naturalización del fenómeno nacional que no se toma nunca como objeto de investigación sistemático (Larraín 1989, Rosdolsky 1986, Sayer 1991).

Los problemas de esta visión sobre el surgimiento de la sociología no fueron objeto de revisión durante bastante tiempo, pero en el último tiempo sus imprecisiones 
han comenzado a hacerse evidentes (Turner 1990, Fine 2004, Inglis and Robertson 2008, Chernilo 2008a). Primero, porque la historia de la disciplina no puede narrarse desde el punto de vista del nacionalismo metodológico: para la sociología el estadonación es sin duda la forma más importante de organización socio-política de la vida moderna, pero no es su forma natural o necesaria (Chernilo 2006a). El legítimo interés por la formación y expansión de los estados-nación europeos no es el asunto que guía la agenda de la sociología clásica y a partir del cual subordina el resto de su programa intelectual. Segundo, porque la sociología clásica sí ofrece un concepto de estado-nación como aquella formación socio-política moderna que es capaz de manejar con éxito su propia opacidad histórica, sociológica y normativa. El estadonación ha sido exitoso porque históricamente está en un estado de crisis permanente, casi a punto de desaparecer, y sin embargo consigue reinventarse constantemente y con ello evitar su propio ocaso; porque sociológicamente reclama para sí lealtad absoluta pero es capaz de convivir e incluso someterse a una diversidad de identidades sociales de clase, religiosas o étnicas cuando se ve amenazado; y porque normativamente se basa en una idea de soberanía inviolable que paradójicamente sólo puede justificarse por referencia a principios cosmopolitas que lo trascienden (Chernilo 2007a).Y es en este contexto, tercero, que reaparece con fuerza el problema del universalismo en la constitución de la mirada y objeto de estudio de la sociología (Chernilo 2007b, Turner 2006). Este es el tema que marca el surgimiento de la sociología: la explicación del surgimiento geográfica e históricamente situado de la modernidad europea vis-a-vis el alcance y orientación universal de la misma:

El hijo de la moderna civilización occidental que trata de problemas histórico-universales, lo hace de modo inevitable y lógico desde el siguiente planteamiento: ¿qué encadenamiento de circunstancias ha conducido a que aparecieran en Occidente, y sólo en Occidente, fenómenos culturales que (al menos tal y como tendemos a representárnoslos) se insertan en una dirección evolutiva de alcance y validez universales? (Weber, p. 11, cursivas en el original).

Este es el párrafo con que Weber abre su Sociología de la Religión.Y aunque posiblemente lo hemos escuchado varias veces, no tomamos suficientemente en serio el hecho de que su mención inicial a occidente - con la que por cierto se da inicio a su estudio sobre la relación entre ética económica y religiosa en el protestantismo - no es una referencia autocontenida. Es, por el contrario, un capítulo más y comparativamente breve de sus estudios sobre la relación ética económica y las distintas religiones mundiales: Judaísmo Antiguo, Confucionismo, Taoísmo, Hinduismo, Budismo, Islam. Cierto, se trata de la frase con que se abre el estudio de todas las religiones con alcance civilizatorio y ello indica el ángulo desde el cual se hace la observación. Pero el interés de Weber por el protestantismo no sólo no es distinto al que tiene por las otras religiones, sino que su proyecto trata justamente de explorar qué hace distintas a esas religiones y dónde radica su propio potencial universal. Además, la frase deja 
traslucir también las dudas con que Weber se acerca al problema del universalismo: su nota de precaución entre paréntesis y el uso de la cursiva justamente en "universales". Weber mustra aquí la pretensión universalista de la sociología, pero también el riesgo eurocéntrico que ella tiene inscrito. La relación entre eurocentrismo y universalismo es más problemática de lo que quisiéramos o, dicho de otra manera, eurocentrismo no es lo opuesto de universalismo, sino un universalismo homogenizador antes que pluralista, apresurado antes que autocrítico y reificado antes que reflexivo y procedimentalizado.

En una interesante publicación reciente, Gurminder Bhambra se hace cargo justamente de este tema y tanto sus aciertos como sus dificultades nos ayudan a entender, desde la perspectiva del eurocentrismo, los problemas que enfrenta la pretensión universalista de la sociología. Ella define eurocentrismo como "la creencia, implícita o no, en la significación histórico-mundial de eventos que se supone se desarrollaron endógenamente al interior de la esfera geográfico-cultural de Europa" (Bhambra 2007: 5) y sostiene que no es posible "continuar privilegiando a Occidente como el 'hacedor' de la historia universal" (Bhambra 2007: 2). El acierto fundamental de la crítica de Bhambra radica en su demostración de que los estudios postcoloniales como parte de un movimiento más amplio de "estudios subordinados" entre los que se incluyen también los estudios de género - no consiguen en realidad ir mucho más allá del eurocentrismo que critican. Por un lado, porque su supuesta representación de los subordinados no puede sino terminar haciendo abstracción de la especificidad de las distintas voces que intenta representar, y con eso "re-introduce una pretensión proto-universalista que no es tan distinta a la que se atribuye a la epistemología convencional" (Bhambra 2007: 29). O, pecando por el lado contrario, cuando los mismos estudiosos postcolonialistas reclaman en contra del esencialismo eurocéntrico y se arrogan la vocería de la diversidad cultural, el pluralismo y la contingencia de la formas de vida, en los hechos ellos requieren de ese mismo esencialismo que critican "como condición necesaria para la práctica política" (Bhambra 2007: 30). Bhambra tiene razón y sus argumentos hacen evidentes las limitaciones tanto epistemológicas como normativas del relativismo: una situación no puede ser descrita como de subordinación sin un estándar normativo potencialmente universalizable desde el que juzgar la situación como tal y la resistencia contra la dominación requiere de abstracciones también potencialmente universalizables.

Habiendo rechazado el relativismo, Bhambra (2007: 145) critica también a la tradición sociológica como un todo por Eurocéntrica, puesto que sus "categorías no son universales sino que encarnan una forma de eurocentrismo". Tanto las teorías de la modernización de los años cincuenta como sus más recientes versiones de teorías de las modernidades múltiples o entrelazadas, serían todas igualmente eurocéntricas, puesto que si bien las segundas critican los problemas metodológicos de las primeras - estudiar lo que sucede en distintas partes del globo a partir de parámetros europeos 
- ellas mismas no cuestionan nunca el dato eurocéntrico fundamental: "los orígenes europeos de la modernidad no pueden negarse" (Bhambra 2007: 152). La sociología deviene así en la ciencia dedicada al estudio del eurocentrismo o, siguiendo la clásica crítica occidentalista de Edward Said (1978) a las humanidades, la sociología habría devenido en algo así como el punto ciego del eurocentrismo europeo. Estando de acuerdo con su rechazo al relativismo y al eurocentrismo, obviamente no comparto su visión de la historia y características principales de la sociología (Chernilo 2007a). Pero ahora no me interesa criticar su imagen de la disciplina sino mostrar que las dificultades en que incurre se derivan de su propia crítica al eurocentrismo. Su propuesta de una metodología de "historias conectadas" (Bhambra 2007: 30-33) para superar la imagen autocontenida y las explicaciones endógenas de la modernidad europea no parece sin embargo ser capaz de romper el círculo vicioso entre relativismo y eurocentrismo. Ello requiere, para decirlo en los términos que prefiero, una pretensión decididamente universalista.

Primero, la crítica al carácter autocontenido y endógeno de las visones eurocéntricas es en realidad una extensión de la crítica al nacionalismo metodológico que en su momento se concentró en la falacia de entender los procesos de desarrollo nacional también de forma endógena (Martins 1974, Smith 1979). El problema, sin embargo, es que el enemigo no es tanto el endogenismo per se sino la disolución de las explicaciones sociológicas en asuntos geográficos (Luhmann 2007) o en problemas de escala (Archer 1995). Pero la dificultad de fondo radica en otro lado. Al atribuir a esa unidad cualidades que no posee - coherencia interna, continuidad temporal, autocontención normativa $-\mathrm{y}$ al hacerla coextensiva con la tradición intelectual con que se la estudia - la sociología - se hace en los hechos imposible proponer cualquier afirmación con sentido sobre tal unidad. Eso es justamente lo que sucede cuando la crítica al nacionalismo metodológico de Ulrich Beck se extiende hasta hacerse indistinguible con la sociología misma: simplemente quedamos incapacitados para comprender los rasgos más básicos del estado-nación (Chernilo 2006a). En este caso, la exagerada crítica de eurocentrismo dice más sobre quien hace el comentario Bhambra y no la tradición sociológica - que sobre las especificidades del objeto que se propone estudiar: el origen local pero potencial universal de la modernidad que surge en Europa. ¡El eurocentrismo se ha transformado en un fantasma tan paralizante que su miedo simplemente impide cualquier mención a Europa!

El asunto, en definitiva, se juega en que es necesario profundizar en vez de abandonar la pretensión universalista de la sociología.Y eso es tal vez lo que explica que cuando se enfrenta a la disyuntiva relativismo versus eurocentrismo, Bhambra utilice expresiones incómodas del tipo "proto-universalismo", como en una cita anterior o, en el último párrafo de su libro, "falso-universalismo" (Bhambra 2007: 155). Pero contra esos universalismos de segunda clase, lo que necesitamos es un universalismo más refinado y reflexivo. La vocación intelectual de la naciente disciplina puede 
entonces expresarse en una tensión que se mueve entre entender el universalismo como una pretensión inalcanzable pero que sirve de guía para la investigación y concebirlo como la determinación definitiva de un conjunto de contenidos específicos. Cuando se cae en la segunda versión lo que surge es el eurocentrismo, pero cuando se expresa la primera la sociología hace del universalismo su propio ideal regulativo (Kant 2002, Emmet 1994, Chernilo 2004, 2007). La orientación universalista de la sociología se ve entonces satisfecha a un nivel más abstracto y no en el hecho de quedar anclada a una u otra visión particular. Se refiere a un estándar general e inalcanzable que orienta la investigación sin llegar él mismo a satisfacerse nunca en un objeto de investigación empírico. Es por eso que se lo refiere como una pretensión, como una aspiración que puede verse defraudada una y mil veces pero que no por eso deja de tener un rol que jugar en la orientación de la acción.

La crítica de eurocentrismo contra la sociología clásica dice relación con la reificación de la pretensión universalista de conocimiento; con el intento por encontrar, de una vez y para siempre, el contenido último de ese universalismo en un conjunto bien delimitado de características esencialmente europeas. Pero el eurocentrismo no consiste sólo en el intento por poner a Europa como centro organizativo y horizonte futuro de la sociedad moderna. También es eurocéntrica aquella formulación que, en vez de justificar argumentativamente su aspiración de universalidad se contenta con afirmarla en razón de una prioridad histórica, ubicación geográfica o acomodación cultural - lo mismo da que tal característica sea supuesta o real. La crítica de eurocentrismo hace mella en la pretensión universalista de la sociología sólo en la medida que la sociología cae, por decirlo de algún modo, por debajo del umbral de sus propias posibilidades cognitivas. Por el contrario, cuando se mantiene al nivel más abstracto y queda abierta, sistemáticamente, a su propio refinamiento reflexivo, lo que entonces parecía universalista puede por cierto demostrarse eurocéntrico y eso, lejos de hacernos abandonar el proceso, le da un nuevo ímpetu. Junto con rechazar los contenidos específicos que se han tornado problemáticos, el universalismo sigue operando como una pretensión y se evita entonces arrojar al bebé junto con el agua de la bañera.Y si bien los sociólogos clásicos no hicieron un uso siempre consistente del universalismo que está a la base de sus teorías, ellos están igualmente lejos haber sido presa del tipo de eurocentrismo que se les imputa.

\section{Postmodernismo, globalismo y universalismo hoy}

La historia de la sociología puede narrarse desde el punto de vista del despliegue de esta pretensión universalista, en sus distintas planos y versiones, en sus casi doscientos años de historia. Ello no implica, sin embargo, hacer esa narración como una marcha teleológica donde los sociólogos contemporáneos tienen todo a su favor cuando su trabajo se compara con el de sus predecesores. La posición que aquí se adopta 
favorece un acercamiento donde si bien hay aprendizaje respecto de los errores del pasado, los aciertos y desaciertos se dividen, en principio, por partes iguales entre escritores pretéritos y presentes. Sin duda podemos sacar lecciones de la historia, pero los gigantes pueden igualmente ser demasiado grandes y sus hombros quedarnos demasiado altos. Quiero entonces concluir este texto con una reflexión, algo más breve que las secciones anteriores, sobre los desafios que la pretensión universalista de la sociología ha enfrentado en las últimas décadas. El postmodernismo es la corriente que asestó el golpe más reciente a la orientación universalista de la sociología en tanto provoca una crisis en la sociología a partir de la crisis del diagnóstico de crisis con que opera la disciplina. Así, para mediados de la década del setenta del siglo pasado, el conjunto amplio y heterogéneo de discusiones y posiciones que se agruparon bajo el paraguas del postmodernismo hizo efectivamente tambalear la pretensión universalista de la sociología y de las ciencias sociales en general. La variedad de objetos de crítica del postmodernismo - positivismo, individualismo metodológico, teleologías históricas, euro- y androcentrismo - tienen como denominador común el tipo de orientación universalista en que se fundan las corrientes principales de la sociología de su tiempo. No es por ello de extrañar que la crítica postmoderna haya hecho del universalismo el término con que referir a todos los pecados de las ciencias sociales: fin de los metarrelatos (Lyotard 1987), desaparición del individuo moderno como subjetividad autónoma y creadora (Foucault 1975), la noción baudrillana de simulacro (Baudrillard 1978) y la deconstrución como fundamento (ojo con la paradoja) epistemológico (Derrida 1997).

Después de lo que pareció ser la consolidación de los temas centrales del postmodernismo, el cambio de siglo dio lugar a un nuevo revisionismo que si bien no se propuso desandar la crítica postmoderna, obligó en los hechos a hacer frente a varios de sus resultados más importantes. El más reciente debate sobre la globalización vino a evidenciar que muchas de las tendencias históricas más importantes de las últimas décadas tienen en los hechos consecuencias análogas a lo largo y ancho del globo. Si bien el globalismo ha sido descrito como la llegada tardía de la crítica postmoderna a las corrientes principales de la sociología (Wagner 2001), esta caracterización esconde el hecho de que en la práctica la agenda de la nueva ortodoxia globalista fue más bien anti-postmoderna en su énfasis en las consecuencias homogenizadoras de prácticas sociales y culturales, la expansión del capitalismo y flujos de información por todo el globo en tiempo real, el surgimiento de un nuevo régimen transnacional de derechos humanos, etc. Desde un marco de referencia teórico débil y deficientemente fundamentado, las afirmaciones globalistas tienen al menos el mérito de mostrar la vanidad algo vacía que se esconde en los argumentos sobre la diferencia e inconmensurabilidad de la crítica postmoderna (Chernilo 2007a, Fine y Chernilo 2004, Outhwaite 2006). Eso, aunque ya en la década de los sesenta, mientras era profesor en Ghana, Norbert Elías (1995) decía que, nos guste o no, los aviones vuelan de la misma manera en África y en Europa.Y a inicios del siglo XX, el propio Max 
Weber (2001) insistía en que si su sociología comparada no le hacía sentido a un investigador proveniente de China, entonces se trataba de una disciplina sin valor intelectual ni mucho menos sentido práctico.

En lo que se refiere al refinamiento y reflexivización de la pretensión universalista de la sociología, el desafío que tenemos entre manos puede plantearse más o menos de la siguiente manera. Debemos, primero, rechazar los excesos que se derivan tanto de la noción postmoderna del fin de todo lo moderno, como de la idea globalizadora de que las nuevas tendencias mundiales son un fenómeno socioculturalmente homogenizador e históricamente sin precedente. El postmodernismo hierra al enfocar sus dardos contra toda clase de pretensión universalista y el globalismo al pretender reintroducirlo sin las necesarias precauciones. Ambos postulados se parecen no sólo en su unilateralismo sino en su carácter reduccionista y, vistas así las cosas, la imagen postmoderna del "fin de la modernidad" es mortalmente parecida a la imagen globalista de la "consumación de la modernidad". Debemos, sin embargo, ser igualmente capaces de extraer el momento de verdad que se aloja en ambas críticas: la tesis postmoderna de que es injustificado hacer descansar la confianza epistemológica de nuestras proposiciones en posiciones sociales o históricamente privilegiadas y la tesis globalizadora de que la condición actual de la modernidad debe intentar conceptualizarse desde la perspectiva de una sociedad que se ha hecho efectivamente mundial. Al despejar los excesos tanto del postmodernismo como del globalismo, la posibilidad que se abre ante nosotros es conceptualizar la encrucijada actual de la modernidad como un desacoplamiento entre el particularismo histórico y geográfico de sus orígenes europeos y el hecho de que sus desarrollos y tendencias principales han empezado a lograr el tipo de impacto universalista que estaba alojado en su vocación original. El desafio es intentar una reevaluación del proceso simultáneo de expansión universal de la modernidad vis-à-vis el declive de su matriz europea.

Es preciso abandonar una idea de universalismo como fundamento incuestionado, conjunto de contenidos fijo o protocolo estricto de medidas a cumplir, y hablar más bien de una pretensión de conocimiento universalista que opera más bien como un horizonte congnitivo. Este paso, me parece implica al menos las siguientes dos cosas. Primero, aceptar que estamos en presencia de una exigencia ineludible si queremos entender las tendencias principales de la modernidad actual. Ello implica la búsqueda de posiciones de observación y análisis que no se identifiquen o mimeticen con los espacios locales $\mathrm{u}$ actores desde los que esas posiciones necesariamente han de emerger. El desafio ahora es rechazar el eurocentrismo, pero no para reemplazarlo con formas aparentemente alternativas pero igualmente reduccionistas como el indigenismo, o los así llamados valores asiáticos (Sen 1997): una interpretación estratégicamente particularista de la declaración de los Derechos Humanos para hacerla compatible con los abusos a las libertades políticas y civiles que se dan en varios de los así llamados tigres asiáticos (Singapur, Corea del Sur, Taiwán). Segundo, que esa 
pretensión universalista solo puede justificarse si se la entiende como una pretensión falible y que permanece abierta a la posibilidad de encontrar formas más abstractas con las que fundamentarla. La pretensión universalista que aquí se intenta justificar puede entenderse como un ideal regulativo - ella no se traduce nunca en una afirmación única y definitiva sobre lo que es o sobre las vías de acceso al conocimiento de lo que es, sino que se mantiene a un nivel más abstracto como aquella inquietud sobre condición de posibilidad del conocimiento sociológico.

Esa es justamente la seducción que la idea de "post-universalismo" ejerce en autores contemporáneos como Gerard Delanty o Ulrich Beck (Fine 2007: 14-17). Con ese paradójico término, ellos parecen querer expresar justamente el tránsito desde una concepción sustancialista de universalismo a lo que en este texto he llamado la pretensión universalista del conocimiento sociológico. La forma espuria de universalismos que ellos rechazan no es otra cosa que el contenido eurocéntrico de la sociología y su noción de post-universalismo sería, por el contrario, crítica, dialógica y abierta al reconocimiento de la pluralidad de cosmovisiones que cohabitan en el mundo moderno (Delanty 2006: 35). Si aquí se prefiere la idea de pretensión universalista no es sólo para evitar los problemas asociados al uso del prefijo "post", sino para hacer ver que se trata de una radicalización o incluso reflexivización de los postulados y formas de proceder científicas de la sociología pasada y presente, pero no de su abandono ni superación. Se trata de la profundización en una tradición intelectual y no de una separación tajante entre historia de la ideas y teoría sistemática. Debemos intentar comprender la verdaderamente moderna condición de la modernidad actual sin reintroducir, por la ventana o la puerta de atrás, el tipo de generalizaciones espurias que, con tanto esfuerzo, han ido lentamente mostrando sus insuficiencias. Pero la sociedad contemporánea no se hace cada vez más moderna porque se parezca cada vez menos a Europa o Estados Unidos. Y su modernidad no radica tampoco en el hecho de haber adquirido recientemente un carácter supuestamente híbrido: la modernidad de la sociedad contemporánea se expresa en que se parece cada vez más a sí misma. 


\section{Bibliografia}

Albrow, M. (1996): The Global Age, Cambridge: Polity Press.

Archer, M. (1995): Realist Social Theory: The morphogenetic approach, Cambridge: Cambridge University Press.

Aron, R. (1965): Main Currents in Sociological Thought, 2 Vols., Londres: Weidenfeld and Nicolson.

Barbalet, J. (2005): 'Smith's Sentiments (1759) and Wright's Passions (1601): The Beginnings of Sociology', British Journal of Sociology 56 (2): 171-189.

Baudrillard, J. (1978): Cultura y Simulacro, Barcelona: Kairos.

Beck, U. (2000): What is globalization?, Cambridge: Polity Press.

Beck, U. (2006): Cosmopolitan Vision, Cambridge: Polity Press.

Bhambra, G. (2007): Rethinking Modernity: Postcolonialism and the sociological imagination, Basingstoke: Palgrave.

Cassirer, E. (1979): The Philosophy of the Enlightenment, Nueva Jersey: Princeton University Press.

Chernilo, D. (2004): 'La sociedad como ideal regulativo', http://www.moebio.uchile.cl/21/frames02.htm.

Chernilo, D. (2006a): 'Social theory's methodological nationalism: myth and reality', European Journal of Social Theory 9 (1): 5-22.

Chernilo, D. (2007a): A social theory of the nation-state: The political forms of modernity beyond methodological nationalism, Londres: Routledge.

Chernilo, D. (2007b): 'A quest for universalism: Re-assessing the nature of classical social theory's cosmopolitanism', European Journal of Social Theory 10 (1): 17-35.

Chernilo D. (2007c): 'Universalismo y Cosmopolitismo en la teoría de Jürgen Habermas', Estudios Públicos 106: 175-203.

Chernilo, D. (2008a): 'Classical Sociology and the nation-state: A reinterpretation', Journal of Classical Sociology 8 (1):27-43.

Chernilo, D. (2008b): 'Cosmopolitanism and social theory', en Turner, B. S. (ed.), The Blackwell Companion to Social Theory, Oxford: Blackwell. 
Chernilo, D y Mascareño, A. (2005): 'Universalismo, particularismo y sociedad mundial: Obstáculos y perspectivas de la sociología en América Latina', Persona y Sociedad 19 (3): 17-45.

d'Entrèves, A. (1970): Natural Law, Londres: Hutchinson

Dahrendorf, R. (1958): 'Out of utopia:Towards a reorientation of sociological analysis', American Journal of Sociology 64 (2): 115-27.

Delanty, G. (2006): 'The cosmopolitan imagination: critical cosmopolitanism and social theory', British Journal of Sociology 57 (1): 25-47.

Derrida, J. (1997): El tiempo de una tesis. Deconstrucción e implicaciones conceptuales. Barcelona: Proyecto a Ediciones.

Durkheim, E. (1915): Germany above all. París: Collin.

Durkheim, E. (1966): Lecciones de Sociología, Buenos Aires: Shapire.

Emmet, D. (1994): The role of the unrealisable: $A$ study in regulative ideals. Nueva York: St. Martin's Press.

Elias, N. (1995): Mi Trayectoria Intelectual, Barcelona: Península.

Fine, R. (2001): Political investigations. Hegel, Marx, Arendt, Londres: Routledge.

Fine, R. (2002): Democracy and the rule of law, Nueva Jersey:The Balckburn Press.

Fine, R. (2004): 'Cosmopolitismo sin “ismo": Un ensayo reconstructivo', Persona y Sociedad XVIII (2): 239-62.

Fine, R. (2007): Cosmopolitanism, Londres: Routledge.

Fine, R. and Chernilo, D. (2004): 'Between past and future:The equivocations of the new cosmopolitanism', Studies in Law, Politics, and Society 31:25-44.

Foucault, M. (1975): El Nacimiento de la Clínica, México D. F.: Siglo Veintiuno.

Gay, P. (1977): The Enlightenment Vol. 2: The Science of Freedom, Nueva York: W. W. Norton.

Giddens, A. (1971): Capitalism and Modern Social Theory, Cambridge: Cambridge University Press.

Giddens, A. (1973): The Class structure of the Advanced Societies, Londres: Hutchinson.

Haakonssen, K. (1996): Natural Law and Moral Philosophy, Cambridge: Cambridge University Press. 
Habermas, J. (1987): Teoría y praxis, Madrid:Tecnos.

Habermas, J. (1989): Teoría de la Acción Comunicativa Vol. 1, Madrid:Taurus.

Habermas, J. (1990): Conocimiento e interés, Madrid:Taurus.

Harrington, A. (2005): 'Introduction to Georg Simmel's Essay "Europe and America in World history"', European Journal of Social Theory 8 (1): 63-72.

Hawthorn, G. (1987): Enlightenment and Despair. A History of Social Theory, Cambridge: Cambridge University Press.

Heilbron, J. (1995): The rise of social theory, Cambridge: Polity Press.

Hobsbawm, E. (2001): La Era de la Revolución 1789-1848, Barcelona: Crítica

Hochstrasser, T. (2000): Natural law theories in the early enlightenment, Cambridge: Cambridge University Press.

Inglis, D. and Robertson (2008): 'The Elementary Forms of Globlality: Durkheim and the Emergence and Nature of Global Life', Journal of Classical Sociology 8 (1): $5-25$.

Kant, I. (2002): Crítica de la razón pura, Madrid: Alfaguara.

Kim, K. (2005): Discourses on Liberation: An Anatomy of Critical Theory, Boulder, Colorado: Paradigm Publishers.

Koselleck, R. (2007): Crítica y Crisis: Un estudio sobre la patogénesis del mundo burgués, Mardid:Trotta - Universidad Autónoma de Madrid.

la Torre, M. (2006): 'On Two Distinct and Opposing Versions of Natural Law: "Exclusive" versus "Inclusive", Ratio Juris 19 (2): 197-216.

Larraín, J. (1989): Theories of development. Capitalism, colonialism and dependency, Cambridge: Polity Press.

Löwy, M. (1992): Redemption and Utopia, Londres:The Athloe Press.

Luhmann, N. (2007): La Sociedad de la Sociedad, México D.F.: Herder - Universidad Iberoamericana.

Lyotard, F. (1987): La Condición Postmoderna, Madrid: Cátedra.

Marcuse, H. (1973): Reason and Revolution, Londres: Routledge and Kegan Paul.

Martins, H. (1974): 'Time and theory in sociology', en Rex, J. (ed.) Approaches to sociology, Londres: Routledge and Kegan Paul. 
Mills, C.W. ( 1994): La Imaginación Sociológica, Santiago: FCE.

Nisbet, R. (1967): The Sociological Tradition, Londres: Heinemann.

Outhwaite, W. (2006): The future of society. Oxford: Blackwell.

Parsons, T. (1968): The Structure of Social Action, 2 Vols., New York:The Free Press.

Rommen, H. (1998): The Natural Law: A Study in Legal and Social History and Philosophy, Indianapolis: The Liberty Fund.

Rosdolsky, R. (1986): Engels and the 'nonhistoric' peoples: the national question in the revolution of 1848, Glasgow: Critique Books.

Sayer, D. (1991): Capitalism and Modernity, Londres: Routledge.

Said, E. (1978): Orientalism, Londres: Penguin.

Seidman, S. (1983): Liberalism and the Origins of European Social Theory, Oxford: Basil Blackwell.

Sen,A. (1997):'Human Rights and Asian Values', http://www.mtholyoke.edu/acad/intrel/sen.htm (revisado el 19 de marzo de 2008).

Smith, A. (1979): Nationalism in the twentieth century, Oxford: Martin Robertson.

Smith, A. (1983): 'Nationalism and classical social theory', British Journal of Sociology 34 (1): 19-38.

Strauss, L. (1974): Natural Right and History, Chicago: The University of Chicago Press.

Swingewood, A. (1970): 'Origins of Sociology: The Case of the Scottish Enlightenment', British Journal of Sociology 21 (2): 164-180.

Tuck, R. (1981): Natural Rights Theories: Their Origin and Development, Cambridge: Cambridge University Press.

Turner, B. S. (1990): ‘The two faces of sociology: Global or national?' en Featherstone, M. (ed.) Global culture. Nationalism, globalisation and modernity, Londres: Sage.

Turner, B. S. (2006): 'Classical sociology and cosmopolitanism: A critical defence of the social', British Journal of Sociology 57 (1): 133-55.

Urry, J. (2000): Sociology beyond societies, Londres: Routledge.

Wagner, P. (2001): Not All that is Solid Melts into Air, Londres: Sage.

Weber, M. (1993): El político y el cientifico, Madrid:Alianza 
Weber, M. (1998): Ensayos sobre sociología de la religión Vol. 1, Madrid:Taurus.

Weber, M. (2001): Ensayos sobre metodología sociológica, Buenos Aires: Amorrortu.

Zeitlin, I. (1990): Ideology and the Development of Sociological Theory, Nueva Jersey: Prentice-Hall. 